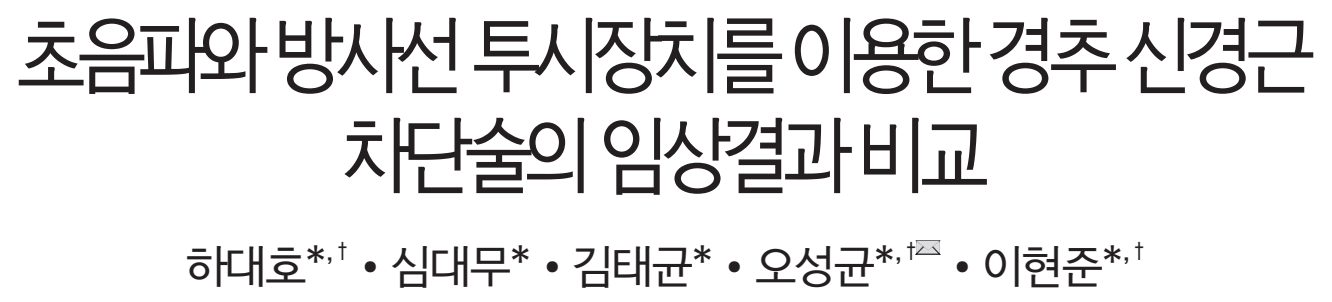

*원광대학교 의과대학 원광의과학연구소 정형외과학교실, ${ }^{\dagger}$ 원광대학교 의과대학 산본병원 정형외과학교실

\title{
Comparison of the Clinical Outcomes of an Ultrasound-Guided and C-Arm Guided Cervical Nerve Root Block
}

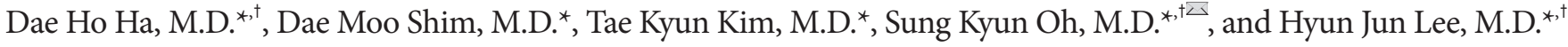 \\ ${ }^{*}$ Department of Orthopedic Surgery, Institute of Wonkwang Medical Science, School of Medicine, Wonkwang University, Iksan, \\ ${ }^{\dagger}$ Department of Orthopedic Surgery, Sanbon Hospital, School of Medicine, Wonkwang University, Gunpo, Korea
}

Purpose: This paper compares the clinical outcomes of patients who were treated with a cervical nerve block by ultrasound and $\mathrm{C}$-arm and reports the complication.

Materials and Methods: A total of 97 patients were treated with an ultrasound-guided nerve root block from May 1, 2015 to February 8, 2018. On the other hand, 94 patients were treated with a $\mathrm{C}$-arm guided nerve root block. The consequences of the cervical pain and the radiating pain before and after the procedures were reviewed using the verbal numeric rating scale (VNRS). In addition, the complications related to the procedures from the daily notes from the chart were inspected.

Results: Sixty-six cases out of 97 cases of ultrasound-guided nerve root block were enrolled in the study. The average age of the patients was 57 years, including 41 males and 25 females. Seventy seven out of 94 cases by a C-arm guided root block were included in the study. The average age of the patients was 55 years, including 40 males and 37 females. Before the nerve root block, the mean numeric rating pain scale (NRS) of the cervical pain in ultrasound-guided block decreased from 5.4 points to 2.7 points at three weeks and 1.4 points at six weeks $(p=0.0023, p<0.001)$, and 3.1 points in the $C$-arm $(p<0.001, p<0.001)$ at three weeks and 1.5 points at six weeks $(p<0.001, p<0.001)$. In the case of radiating pain, the mean NRS in the ultrasound-guided nerve root block group improved from 6.3 points after the procedure to 2.8 points at three weeks and 1.5 points at six weeks $(\mathrm{p}<0.001, \mathrm{p}<0.001)$. In the $\mathrm{C}$-arm guided nerve root block group, the NRS improved from 7.4 points after the procedure to 3.3 points at three weeks and 1.9 points at six weeks. In the case of complications, Horner's syndrome and propriospinal myoclonus were observed in one case of $\mathrm{C}$-arm guided block group.

Conclusion: The clinical results of the patients who underwent ultrasound-guided cervical nerve root block were not significantly different from those who underwent a C-arm guided cervical nerve root block.

Key words: cervical vertebrae, radiculopathy, diagnostic imaging

\footnotetext{
Received April 17, 2019 Revised May 14, 2019 Accepted July 19, 2019

Correspondence to: Sung Kyun Oh, M.D.

Department of Orthopedic Surgery, Sanbon Hospital, School of Medicine, Wonkwang University, 327 Sanbon-ro, Gunpo 15865, Korea

TEL: +82-31-390-2224 FAX:+82-31-398-2223 E-mail: niceo@hanmail.net ORCID: https://orcid.org/0000-0001-6003-6855
}

*This research was supported by 2019 research grant from Wonkwang University.

\section{서 론}

경추 추간판 탈출증에 의한 방사통의 치료 시 약물치료 및 물리 치료 그리고 신경근 차단술 등의 대증 치료가 주를 이루고 있으 며 이를 통해 $90 \%$ 이상에서 수술을 피할 수 있고 자연 경과 역시 양호한 결과를 얻을 수 있다고 알려져 있다. ${ }^{1)}$ 신경근 차단술은 국 소마취제와 스테로이드 약물의 진통 작용과 항염 작용에 기반하 
Clincal Outcomes of an Ultrasound Guided Cervical Root Block

며 선택적으로 영상 유도하에 효과적으로 시행된 경우 치료적 목 적 이외에도 진단적 가치를 지닐 수 있다. ${ }^{2,3)}$ 또한 C-arm 및 컴 퓨터 단층촬영(computed tomography) 같은 방사선 유도하에 시행되는 방법 이외에도 최근에는 초음파 유도하에 신경근 차단 술 혹은 내측지 차단술을 시행하고 이에 대한 임상결과를 보고하 는 문헌들이 늘어나고 있다. ${ }^{4-7)}$ 초음파 영상 기술의 발달과 함께 방사선 노출이 없다는 장점 이외에도 혈관 천자나 중요한 장기의 천자, 신경 내 주사 등의 합병증을 줄일 수 있다고 알려져 근골격 계 영역에서 초음파 이용이 증가하고 있다. 특히 경추 신경근 차 단술 시행 시 단순 방사선 투시 혹은 컴퓨터 단층촬영 유도 시에 도 동맥 내 주사에 의한 혈전 혹은 혈관 경축(spasm)으로 인한 척수 혹은 소뇌 경색이 발생하여 안전성에 대한 논란이 보고된 바 있다. ${ }^{8)}$ 이에 저자들은 방사통을 호소하는 경추 추간판 탈출증 환자에서 초음파 유도하 경추 신경근 차단술을 시행하고 이들의 임상결과 및 합병증에 대해 방사선 투시하 시행된 환자들과 비교 분석하여 초음파 유도하 경추 신경근 차단술의 안정성과 정확성 에 대해 보고하고자 하였다.
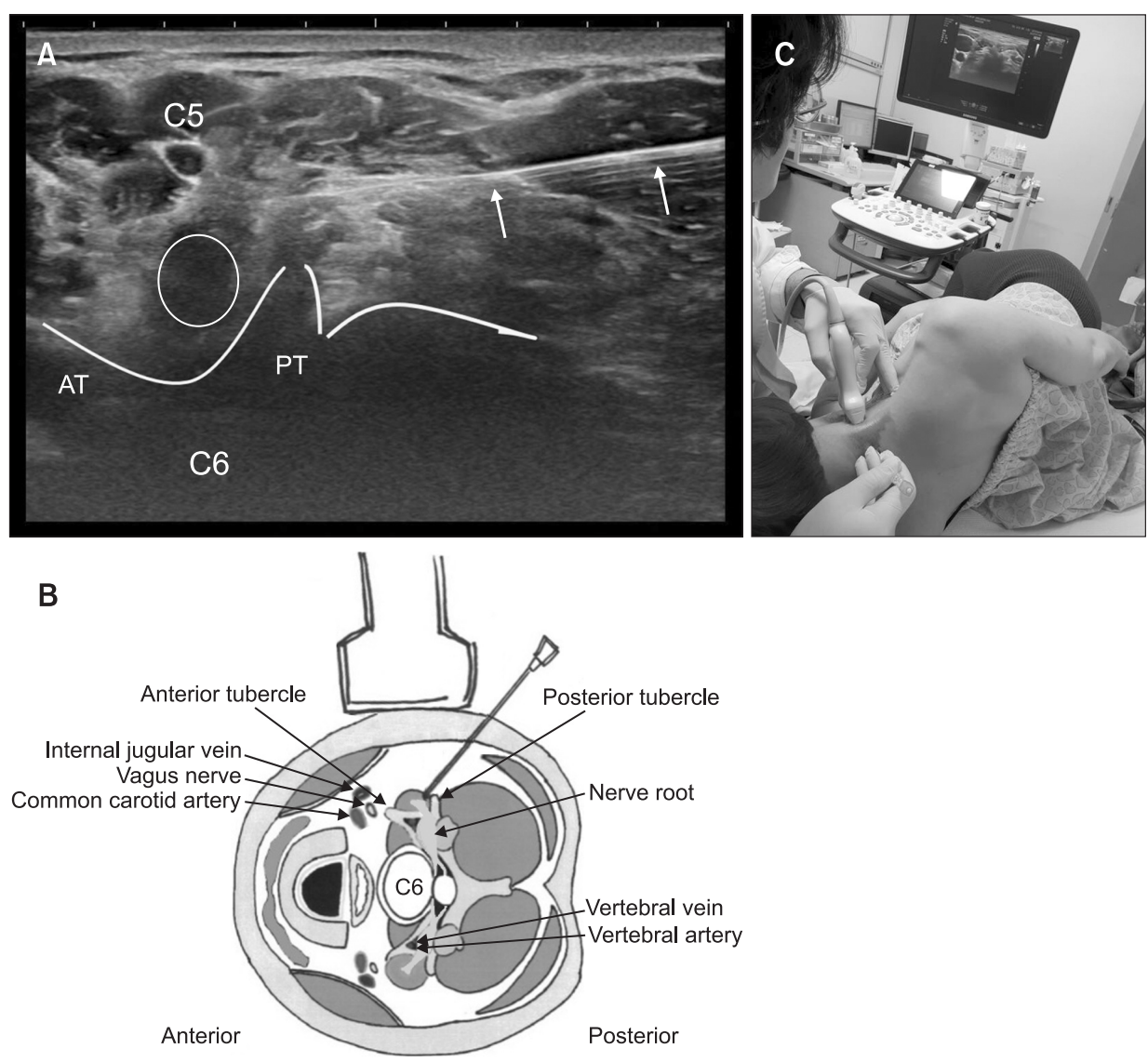

\section{대상 및 방법}

2010년 6월부터 2018년 2월까지 경추 추간판 탈출증으로 진단 되어 원광대학교 산본병원 정형외과에서 일측 방사통에 대해 경 추 신경근 차단술을 시행 받은 후 6주 이상 추시되는 191 명의 환 자를 대상으로 하였으며 본 연구는 원광대학교 산본병원 임상연 구윤리위원회(Institutional Review Board)의 승인을 받아 진 행하였다(WMCSB 201811-84). 모두 교신 저자에 의해 시행된 증례로 경추 자기공명검사를 통해 진단된 추간판 탈출증에 의 한 방사통으로 spurling 징후 양성 혹은 견관절 외전 호전 검사 (abduction relief test) 양성인 환자들을 대상으로 하였다. 방사 선 유도하 경추 신경근 차단술은 모두 수술장에서 C-arm 투시 하에 시행하였고 2010년 6월부터 2017년 8월까지 94예의 환 자가 대상 환자군에 해당되었다. 초음파 유도하 경추 신경근 차 단술은 모두 외래 초음파실에서 시행하였으며 2015년 5월부터 2018년 2월까지 97예의 환자가 해당되었다. 응급실을 통해 입 원한 환자를 제외하고는 모두 외래에서 시행하였으며 외래에서 1 주 후 간격으로 3 회 시행함을 원칙으로 하였다. 두 군 모두 21 gage spinal needle을 이용하여 부피바케인 $1 \mathrm{ml}$ 와 덱사멕사존 $1 \mathrm{ml}$ 를 섞어 목표 신경근에 $1 \mathrm{ml}$ 를 주사하였다. C-arm을 이용
Figure 1. (A) Axial transverse ultrasound image showing a needle approaching the $\mathrm{C} 6$ root between the anterior and posterior tubercles. Round circle indicates C6 root, white lines indicate bony margin around tubercle. (B) Illustration showing the anatomic structures at the C6 level and the orientation of the transducer. (C) Picture shows the patient's position and the transducer for the axial view. AT, anterior tubercle; PT, posterior tubercle. 
Dae HoHa, etal.

하는 경우 환자의 측와위에서 얻어지는 신경공 영상을 확인한 후 목표 신경근을 향해 경부의 측방에서 접근하였고 초음파를 이용 하는 경우 환자는 측와위에서 전측방에 초음파의 탐지자를 위치 시켜 횡축 영상하에 전방과 후방 돌기 사이에 위치하고 있는 목 표 신경근을 향해 후방에서 접근하였다(Fig. 1). 영상 유도 방법의 선택은 외래 진료 요일에 따라 방사선 유도하 경추 신경근 차단 술군(이하 방사선군)과 초음파 유도하 경추 신경근 차단술군(이 하 초음파군)으로 나뉘었고, 최초 시행 후 3주, 6주 그리고 3개월, 6 개월, 12 개월 후 외래 정기 방문을 원칙으로 하였으며 외래 방 문 시 마다 경추통과 상지 방사통에 대한 numeric rating pain scale (NRS) 평가를 시행하였다. 다분절 신경근 병증이거나, 교 통사고 및 산업재해와 연관된 경우, 주 증상이 척수병증인 경우 는 연구대상에서 제외하였다. 정기적인 외래 추시를 통해 6주 이

Table 1. Patients' Demographic Data

\begin{tabular}{|c|c|c|c|}
\hline Variable & $\begin{array}{l}\text { C-arm group } \\
(n=77)\end{array}$ & $\begin{array}{l}\text { Ultrasound } \\
\text { group }(n=66)\end{array}$ & $p$-value* \\
\hline Male/Female & $40 / 37$ & $41 / 25$ & 0.221 \\
\hline Mean age (yr) & 55 & 57 & $0.939^{\dagger}$ \\
\hline $\begin{array}{l}\text { Mean injection } \\
\text { number (per person) }\end{array}$ & 2.49 & 2.48 & $0.571^{\dagger}$ \\
\hline \multicolumn{4}{|l|}{ Target root } \\
\hline C5 & 6 & 8 & \\
\hline C6 & 42 & 37 & 0.339 \\
\hline $\mathrm{C7}$ & 26 & 21 & 0.804 \\
\hline $\mathrm{C} 8$ & 3 & 0 & \\
\hline Total & 77 & 66 & \\
\hline
\end{tabular}

Values are presented as number. * $p$-value was calculated by chi-squared test. ${ }^{\dagger} p$-value was calculated by Wilcoxon rank-sum test.
상 외래 추시가 되는 환자를 연구대상으로 하였으며 최종적으로 외래 경과 기록 및 전화 면담을 통해 수술 시행여부를 확인하였 고 191 명의 환자 중 48 명의 환자가 중도 탈락하였고 143 명의 환 자가 연구대상에 해당되었다. 이들은 남성 81명, 여성 62명이었 고 평균연령 값은 55.7세였고 평균 추시기간은 7.6개월이었다. 초음파 유도하 경추 신경근 차단술을 시행한 경우가 66명, 방사 선 유도하 경추 신경근 차단술을 시행한 경우가 77 명이었고, 각 각 두 군의 평균연령은 57세, 55세였고, 남녀 비율은 각각 남성 41 명, 여성 25명; 남성 40 명, 여성 37 명이었다. 추시기간을 제외 하고는 두 군 간의 통계적으로 의미 있는 차이는 보이지 않았다 (Table 1). 두 군 간의 이환 분절 및 목표 신경근 역시 6번 신경근 과 7번 신경근이 가장 많은 차단 목표 신경근이었고 차단술 시행 횟수 역시 각각 2.5 회로 두 군 간의 통계적 차이를 보이지는 않았 다(Table 1).

본원에서 신경 차단술을 시행하고 6주 이상 대증 치료에 실패 한 환자나 상지 마비가 지속 되는 경우 수술을 권유하였으며 추 시 도중 권유 받은 50 명 중 23 명의 환자가 수술적 치료를 받았 다.

통계 분석은 R ver. 3.4 프로그램(Rexsoft Co. Ltd., Seoul, Korea)을 이용하였다. NRS의 중간값의 시술 전과 시술 후 3주, 6주 후 값의 비교는 NRS를 순위변수(ordinal variable)로 보고 비모수 검정인 프리드만 검정(Friedman test)을 시행하고 초음 파와 방사선 두 군의 NRS 비교는 윌콕슨 순위합 검정(Wilcoxon rank-sum test)을 시행하였다. 두 군의 성별 및 이환분절, 수술 환자 비율 등에 대해서는 카이제곱 검정과 윌콕슨 순위합 검정을 시행하였다. p값이 0.05 미만인 경우 통계적 유의성을 보인다고 정의하였다.

Table 2. Clinical Outcomes of Each Group

\begin{tabular}{|c|c|c|c|c|c|c|}
\hline \multirow{2}{*}{ Variable } & & \multicolumn{3}{|c|}{ NRS } & \multicolumn{2}{|c|}{ p-value*(adjusted) } \\
\hline & & Before injection & $3 w k$ & 6 wk & 3 wk & 6 wk \\
\hline \multicolumn{7}{|l|}{ Neck pain } \\
\hline & Ultrasound & $5.4(3-7)$ & $2.7(2-4)$ & $1.4(0-2)$ & 0.0023 & $<0.001$ \\
\hline & C-arm & $6.2(5-8)$ & $3.1(2-4)$ & $1.5(1-2)$ & $<0.001$ & $<0.001$ \\
\hline & $p$-value ${ }^{\dagger}$ & 0.022 & 0.128 & 0.629 & & \\
\hline \multicolumn{7}{|l|}{ Radiating pain } \\
\hline & Ultrasound & $6.3(5-8)$ & $2.8(2-3)$ & $1.5(0-2)$ & $<0.001$ & $<0.001$ \\
\hline & C-arm & $7.4(6-9)$ & $3.3(2-5)$ & $1.9(1-2.6)$ & $<0.001$ & $<0.001$ \\
\hline & p-value ${ }^{\dagger}$ & 0.004 & 0.125 & 0.194 & & \\
\hline
\end{tabular}

Values are presented as the mean (interquartile range). ${ }^{\star} p$-value was calculated by Wilcoxon rank-sum test. ${ }^{\dagger} p$-value was calculated by Bonferroni's correction. NRS, numeric rating pain scale. 
Clincal Outcomes of an Ultrasound Guided Cervical Root Block

Table 3. Operation Rate and Complication

\begin{tabular}{lcc}
\multicolumn{1}{c}{ Variable } & $\begin{array}{c}\text { Ultrasound } \\
\text { group }(\mathrm{n}=66)\end{array}$ & $\begin{array}{c}\text { C-arm group } \\
(\mathrm{n}=77)\end{array}$ \\
\hline Operation recommended & $17(25.7)$ & $33(42.8)$ \\
Operation performed & $6(9.0)$ & $13(16.7)$ \\
$\begin{array}{l}\text { Operation performed/Operation } \\
\text { recommended (\%) }\end{array}$ & 35.2 & 39.3 \\
Complications & $1^{*}$ & $2^{\dagger}$ \\
\hline
\end{tabular}

Values are presented as number (\%). ${ }^{*}$ Temporary hand swelling. ${ }^{\dagger}$ Horner's syndrome and propriospinal myoclonus.

\section{결 과}

\section{1. 임상결과}

경부 통증의 경우 초음파군과 방사선군의 시술 전 NRS의 중간값 은 5.4점과 6.2점 이었으나 시술 3주 후 초음파군에서 2.7점, 방 사선군에서 3.1점으로 두 군에서 모두 통계적으로 시술 전에 비 해 의미 있게 감소하였고( $\mathrm{p}=0.0023, \mathrm{p}<0.001)$, 차단술 3 주 후 경부통의 평가 시 두 군 간의 차이를 보이지는 않았다( $\mathrm{p}=0.128)$. 차단술 6주 후 경부통의 NRS 중간값 역시 1.4점, 1.5점으로 두 군 모두 통계적으로 의미 있게 감소하였고 $(\mathrm{p}<0.001, \mathrm{p}<0.001)$ 6주 후 경부통의 평가 시 두 군 간의 의미 있는 차이를 보이지는 않았다(p=0.629). 두 군 간의 경부 방사통의 경우에도 시술 전 두 군에서 NRS 중간값은 초음파군에서 6.3점, 방사선군에서 7.4점 이었고, 3주 후 2.8점, 3.3점, 6주 후 1.5점, 1.9점으로 두 군 모두 에서 통계적으로 의미 있게 감소하였고 $(\mathrm{p}<0.001, \mathrm{p}<0.001) 3$ 주와 6주 후 방사통의 평가 시 초음파군과 방사선군 간의 의미 있는 차이를 보이지는 않았다( $\mathrm{p}=0.125, \mathrm{p}=0.194)$ (Table 2).

\section{2. 수술 비율 및 합병증}

신경근 차단술 6주 이후에도 두 군에서 시술 전후 통증의 경 감이 없거나 악화하는 경우 수술을 권유하였다. 외래 추시 도 중 수술을 권유한 비율은 초음파군에서 17 명으로 $25.7 \%$ 였고 방사선군의 경우 33 명으로 $42.8 \%$ 였다. 이 중 실제 수술로 이 어진 경우가 초음파군에서 6 명으로 $9.0 \%$ 가 수술을 시행하였 고 방사선군의 경우 13 명, $16.7 \%$ 의 환자가 수술로 이어졌다. 두 군을 종합하면 초음파군의 경우 수술 권유 시 $35.2 \%$ 가 그리 고 방사선군의 경우 수술 권유 시 39.3\%가 수술로 이어졌으며 두 군 간 수술 비율의 통계적 차이는 보이지 않았다( $\mathrm{p}=0.171)$. 합병증의 경우 두 군에서 모두 심각하거나 치명적인 합병증을 보이지 않았으나, 방사선 유도하 차단술 직후 1 예의 환자에서 척 수고유 간대성 근경련을 보인 증례가 있었고, 1 예가 안과에서 교 감신경의 일시적인 차단으로 인한 호너증후군으로 진단되었다. 초음파 유도하 차단군의 경우 1 예에서 시술 후 일시적인 수부 부
종을 호소하였다(Table 3).

\section{고 찰}

신경근 차단술 시 C-arm의 방사선 조사를 최소화하기 위해 납가 운과 보안경등을 착용하지만 최근 연구에 의하면 납가운에 의해 서 약 $1 / 3$ 의 방사선 차단만이 이루어지고 있으며 평균 차단율은 $37.1 \%$ 에 불과하다는 보고가 있다. ${ }^{9.10)}$ 따라서 최소침습 시술이나 수술 시 방사선을 최소화하기 위해서는 납가운이 아닌 다른 술기 를 선택하거나 C-arm 사용 시 로봇팔 등의 더욱 효과적인 방법 이 필요하다고 하였다. ${ }^{9-11)}$ 현재까지 방사선으로부터 수술자를 완 전하게 보호하는 방법은 C-arm 이외의 다른 영상 장비인 초음 파를 사용하는 것이며 초음파의 영상 질의 개선은 컴퓨터 단층촬 영과 유사하거나 혈관 등의 조영에는 실시간으로 더욱 훌륭한 영 상을 제공한다. 요추 신경근 차단술과는 다르게 경추 신경근 차 단술 시 혈관 내 주입과 이로 인한 혈관 경축에 의한 뇌간이나 척 수의 경색이 보고되어 비입자성 스테로이드 사용이 권장되고 있 으므로 방사선 피폭 이외에도 혈관의 실시간 조영이 가능한 점은 혈관 내 주입을 피할 수 있다는 점에서 초음파의 또 하나의 장점 이 될 것이다. ${ }^{6-8)}$

초음파의 이러한 장점에도 불구하고 차단술 자체의 성공률과 임상결과가 표준적인 방법인 방사선(C-arm) 유도하에 시행되는 것보다 낮다면 장점이 상쇄될 수 있다. 따라서 본 연구는 초음파 유도하 경추 신경근 차단술의 임상결과를 기존의 표준적인 방법 인 방사선(C-arm) 유도하 차단술과 비교하고자 하였으며 임상 결과는 경부통과 방사통 모두 통계적으로 유의하게 호전되어 초 음파 유도하 경추 신경근 차단술이 방사선(C-arm) 유도하 차단 술과 성공률이나 정확도가 모두 동등하거나 그 이상일 수 있다는 점을 시사한다고 할 수 있다.

이외에도 저자들이 경험한 장점으로는 조영제를 사용하지 않 고도 더욱더 목표 신경근에 정확하게 약물을 주입할 수 있다는 점, 조영제 유발 알레르기를 피할 수 있다는 점 이외에도 방사선 (C-arm) 유도하 차단술의 경우 목표 신경근이 위치한 신경공 근 처에 바늘 끝을 위치시킨 후 조영제를 주입하여 신경근 주행을 간접적으로 확인하거나 방사통이 유발되는 것으로 차단술의 성 공률이나 정확도를 평가할 수 있으나 초음파 유도 시에는 실시간 으로 신경근을 영상으로 확인하고 신경근 주위로 약물이 주입되 거나 신경근을 바늘이 직접 자극할 때 환자의 증상을 유발시켜 좀더 직접적으로 차단술의 성공 여부나 정확도를 알 수 있다는 장점이 있다.

마지막으로 저자들이 경험한 초음파의 장점은 편리성이다. C-arm 장비의 크기나 수술장 환경에서 시행되어야 한다는 한계 성이 없이 외래의 좀더 좁은 공간에서 손쉽게 시행될 수 있다는 점은 방사선(C-arm) 유도하에 시행할 때에 비해 대상 환자군의 
Dae HoHa, etal.

적응이 더 넓어 질 수 있다고 추론할 수 있다.

본 연구가 후향적 연구이고 6주 후의 비교적 단기간의 임상결 과를 비교하였다는 제한점이 있으나 이후의 장기간의 임상결과 를 비교하기 위해 추시 중 수술로 이어지는 환자의 비율을 조사 하였고, 외래에서 수술 권유 비율과 실제 수술을 받은 환자의 비 율에 대해 서도 조사하였다. 차단술 전 경부통과 방사통의 NRS 는 두 군에서 모두 통계적으로 차이를 보이지 않았으므로 임상 적으로 유사한 환자군이라고 평가할 수도 있으나 경부통, 방사통 모두 방사선(C-arm) 유도하 차단군에서 NRS가 높았다는 점과 수술 권유 비율이 초음파군에 비해 방사선(C-arm)군에서 더 높 았다는 점은 통계적으로 구분해내기 힘들지만 어느 정도 중증의 환자들이 방사선(C-arm)군에 포함되어 있다고 해석하거나 혹은 반대로 경증의 환자가 초음파군에 포함되어 있을 수 있다는 것으 로 해석할 수도 있다. 저자들이 느끼는 초음파의 편리성에 기반 하여 해석하자면 초음파 술기가 방사선(C-arm) 유도하에 시행 되는 것 보다 쉽고 편해 술자가 좀 더 차단술 대상 환자군이 넓어 졌을 가능성으로도 해석할 수 있다. 또한 초음파군에서 수술 환 자의 비율이 낮다는 것에 대해 초음파의 술기가 정확도가 높고 더 효과적이어서 수술로 이어지지 않았을 가능성으로도 해석할 수 있지만 저자들이 조사한 입원환자의 비율이 방사선(C-arm) 군에서 더 많았으므로 더 중증의 환자 비율이 높았을 가능성이 있고 역으로 초음파는 술기가 쉽고 외래에서 비교적 쉽게 행할 수 있으므로 비교적 적응이 넓어서 다른 대증치료 만으로 가능한 환자에게도 초음파 유도하 경추 신경근 차단술을 권유하여 시행 되었을 가능성도 있다.

다만 초음파 유도하 경추 신경근 차단술의 한계점으로는 환 자의 목이 매우 짧거나 비만인 환자의 경우 영상질의 저하로 차 단술의 정확도가 떨어질 수 있으며, 경추 횡돌기의 전방과 후방 의 돌기가 표지자가 되어 목표 신경근을 찾아 낼 수 있으나 제 3,4 번 경추 신경근의 경우 돌기가 매우 작아 해부학적으로 구분 해 내기가 쉽지 않고 제8번 경추 신경근의 경우 쇄골로 인해 초 음파 유도하에 접근하기가 쉽지 않아 본 연구에서도 모두 방사선 (C-arm) 유도하에 시행되었다. ${ }^{4-6)}$

저자들은 초음파의 도플러 기능을 통해 신경근에 인접한 추 골 동맥을 관찰할 수 있으므로 초음파 유도하 경추 신경근 차단 술 시 혈관 내 주사를 피할 수 있고 초음파 유도하 접근법의 경 우 바늘의 경로가 후방에 서 전방으로 이루어 지므로 좀 더 합병 증 비율이 낮을 수 있다고 예측하였으나 본 연구의 경우 약 200 예의 차단술 중에서 의미 있는 합병증은 약 3 예로 안정성에 있어 서 두 군 모두 차이를 보이지는 않았다고 할 수 있다. 다만 방사선 (C-arm) 유도하 차단술군에서 발생한 간대성 근경련의 경우 약 물의 혈관 내 주입에 따른 합병증일 가능성이 높아 적어도 방사 선(C-arm)군에서 혈관 내 주사에 대해 좀 더 주의해야 할 것으로 보인다. ${ }^{812)}$ 그러나 초음파 유도하의 경우도 혈관 내 주사보다는
신경근 주위 염증에 따른 혈관 조직이 발달된 부위에 약물이 주 입되거나 초음파로 관찰되지 않는 신경근에 인접한 작은 혈관들 이 있는 경우는 초음파 유도하에서도 피할 수는 없을 것으로 판 단된다. 방사선(C-arm) 유도하 혹은 초음파 유도하 경추 신경근 차단술 모두 합병증 비율이 낮은 안전하고 효과적인 방법임에는 틀림없으나 추후 대규모 연구를 통해 의미 있는 차이에 대해 검 증이 필요하다고 생각된다.

\section{결 론}

초음파 유도하 경추 신경근 차단술을 시행한 환자들의 임상결과 를 방사선 유도하 경추 신경근 차단술을 시행한 환자들과 비교하 였을 때 통계적으로 차이를 보이지 않았다.

따라서 외래에서 시행하는 초음파 유도하 경추 신경근 차단술 은 경추 추간판 탈출증에 의한 경추통증 및 방사통을 효과적으로 호전시킬 수 있는 방법으로 생각된다.

\section{CONFLICTS OF INTEREST}

The authors have nothing to disclose.

\section{ORCID}

Dae Ho Ha, https://orcid.org/0000-0001-9917-8746

Dae Moo Shim, https://orcid.org/0000-0001-6116-3485

Tae Kyun Kim, https://orcid.org/0000-0001-9276-4419

Sung Kyun Oh, https://orcid.org/0000-0001-6003-6855

Hyun Jun Lee, https://orcid.org/0000-0002-3165-5849

\section{REFERENCES}

1. Rao R. Neck pain, cervical radiculopathy, and cervical myelopathy: pathophysiology, natural history, and clinical evaluation. J Bone Joint Surg Am. 2002;84:1872-81.

2. Antoniadis A, Dietrich TJ, Farshad M. Does pain relief by CT-guided indirect cervical nerve root injection with local anesthetics and steroids predict pain relief after decompression surgery for cervical nerve root compression? Acta Neurochir (Wien). 2016;158:1869-74.

3. House LM, Barrette K, Mattie R, McCormick ZL. Cervical epidural steroid injection: techniques and evidence. Phys Med Rehabil Clin N Am. 2018;29:1-17.

4. Jee H, Lee JH, Kim J, Park KD, Lee WY, Park Y. Ultrasound-guided selective nerve root block versus fluorosco- 


\section{Clincal Outcomes of an Ultrasound Guided Cervical Root Block}

py-guided transforaminal block for the treatment of radicular pain in the lower cervical spine: a randomized, blinded, controlled study. Skeletal Radiol. 2013;42:69-78.

5. Narouze SN, Vydyanathan A, Kapural L, Sessler DI, Mekhail N. Ultrasound-guided cervical selective nerve root block: a fluoroscopy-controlled feasibility study. Reg Anesth Pain Med. 2009;34:343-8.

6. Park KD, Lee WY, Nam SH, Kim M, Park Y. Ultrasound-guided selective nerve root block versus fluoroscopy-guided interlaminar epidural block for the treatment of radicular pain in the lower cervical spine: a retrospective comparative study. J Ultrasound. 2019;22:167-77.

7. Sun SD, Chang BK, Moon SH. Ultrasound-guided intervention in cervical spine. J Korean Orthop Assoc. 2015;50:77-92.

8. Schneider BJ, Maybin S, Sturos E. Safety and complications of cervical epidural steroid injections. Phys Med Rehabil Clin N Am. 2018;29:155-69.

9. Cheon BK, Kim CL, Kim KR, et al. Radiation safety: a focus on lead aprons and thyroid shields in interventional pain management. Korean J Pain. 2018;31:244-52.

10. Hyun SJ, Kim KJ, Jahng TA, Kim HJ. Efficiency of lead aprons in blocking radiation - how protective are they? Heliyon. 2016;2:e00117.

11. Cristante AF, Barbieri F, da Silva AAR, Dellamano JC. Radiation exposure during spine surgery using C-ARM fluoroscopy. Acta Ortop Bras. 2019;27:46-9.

12. Ryu HK, Lee SG, Min BW, Ban JS, Lee JH, Kim EJ. Propriospinal myoclonus after cervical epidural blockade: a case report. Korean J Anesthesiol. 2008;55:391-4. 


\section{초음파와방사선 투시장치를이용한경추신경근 차단술의 임상결과비교 하대호*, • 심대무* - 김태균 ${ }^{*} \cdot$ 오성균 $^{*,+凶} \cdot$ 이현준 $^{* \dagger}$}

*원광대학교 의과대학 원광의과학연구소 정형외과학교실, ${ }^{+}$원광대학교 의과대학 산본병원 정형외과학교실

목적: 초음파 유도하 경추 신경근 차단술을 시행한 환자들의 임상결과를 방사선 유도하 경추 신경근 차단술을 시행한 환자들과 비 교하고 합병증 및 수술 비율 등에 대해 비교하고자 하였다.

대상 및 방법: 경추 추간판 탈출증으로 진단된 환자들에 대해 2015년 5월 1일부터 2018년 2월 8일까지 초음파 유도하 경추 신경 근 차단술을 시행한 97예와 2010년 6월 1일부터 2017년 8월17일까지 방사선 유도하에 시행한 94예 환자들의 경추통과 방사통 을 시술 전과, 3주, 6주 후 verbal numeric rating scale (VNRS)을 이용하여 조사하였고 시술과 연관된 합병증 유무도 의무기록을 통해 조사하였다.

결과: 초음파 유도하 경추 신경근 차단술을 시행한 97예 중 66예가 연구에 포함되었고 이들의 평균 연령은 57세였다. 남성이 41 명 여성이 25명이었고 목표 신경근은 경추 5번이 8예, 6번이 37예, 7번이 21예였다. 방사선 유도하 경추 신경근 차단술을 시행한 94예 중 77예가 연구에 포함되었고 이들의 평균 연령은 55세였다. 남성이 40명, 여성이 37명이었고 목표 신경근은 5번이 6예, 6 번이 42예, 7번이 26예, 8번이 3예였다. 시술 후 경추통의 numeric rating pain scale은 초음파 유도하의 경우 중간값 5.4점에서 3주, 6주에 2.7점, 1.4점으로 감소하였고( $\mathrm{p}=0.0023, \mathrm{p}<0.001)$, 방사선 유도하의 경우 시술 전 중간값 6.2점에서 3주에 3.1 점, 6 주에 1.5점이었다 $(\mathrm{p}<0.001, \mathrm{p}<0.001)$. 방사통의 경우 초음파 유도하 차단술의 경우 시술 전 중간값 6.3점에서 3주에 2.8점, 6주 에 1.5점으로 호전되었고 $(\mathrm{p}<0.001, \mathrm{p}<0.001)$, 방사선 유도하의 경우 시술 전 7.4점, 3주, 6주에 3.3점, 1.9점으로 감소하였다 $(\mathrm{p}$ $<0.001, \mathrm{p}<0.001)$. 합병증의 경우 방사선 유도하 차단술의 경우 호너 증후군이 1 예, 간대성 근경련이 1 예였으며 초음파 유도하 차단술의 경우 일시적인 수부 부종을 호소하는 1 예가 있었다.

결론: 초음파 유도하 경추 신경근 차단술을 시행한 환자들의 임상결과는 방사선 유도하 경추 신경근 차단술을 시행한 환자들과 통 계적 차이를 보이지 않았다.

색인단어: 경추, 신경근 병증, 진단영상

접수일 2019년 4월 17일 수정일 2019년5월 14일 게재확정일 2019년 7월 19일

책임저자 오성균

15865 , 군포시산본로 327, 원광대학교 산본병원 정형외과

TEL 031-390-2224, FAX 031-398-2223, E-mail niceo@hanmail.net, ORCID https://orcid.org/0000-0001-6003-6855

*본 연구는 2019년 원광대학교 연구비 지원에 의하여 수행됨. 